\title{
DECAIMIENTO EXPONENCIAL DE UNA ECUACIÓN DE ONDA CON DISIPACIONES DÉBILES NO LINEALES EN LA FRONTERA Y TÉRMINO FUENTE
}

\author{
E. Cabanillas L. ${ }^{1}$, Raúl M. Izaguirre Maguiña ${ }^{2}$, J. B. Bernui B. ${ }^{1}$ \& $Z$. Huaringa $S .{ }^{1}$
}

Resumen: En este está enfocado en la estabilidad de las soluciones de una ecuación de onda con disipación no lineal débil en la frontera y término fuente. Los resultados son probados gracias al método de caída de potencial, la técnica de los multiplicadores y las nuevas desigualdades de integrales.

Palabras clave: Ecuación de Kirchhoff, Término fuente, Estabilización en la frontera, Continuación única.

\section{EXPONENCIAL DECAY OF WAVE EQUATION WITH A WEAKLY NONLINEAR BOUNDARY DISIPATION AND SOURCE TERM}

\begin{abstract}
In this article, we are concerned with the stability of solutions for the wave equation with a weakly nonlinear boundary dissipation and source term. The results are proved by means of the potential well method, the multiplier technique and a new integral inequality.
\end{abstract}

Key words: Kirchhoff equation, Source term, Boundary stabilization, Unique continuation.

\section{Introduction}

The main purpose of this article is to study the existence of global solutions and the asymptotic behavior of the energy related to a nonlinear wave equation with nonlinear weakly boundary damping and source term. Consider the system

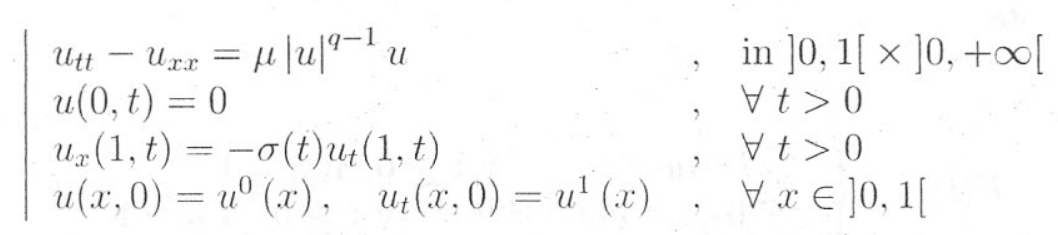

where $a, b, k$ are positive constants and $q>1, \mu \in \mathbb{R}$.

The goal of this work is to state a result of existence and boundary stability of strong and weak solutions to problem (1.1).

${ }^{1}$ UNMSM, Facultad de Ciencias Matemáticas, Lima, Perú, e-mail: cleugenio @yahoo.com

${ }^{2}$ UNMSM, Facultad de Ciencias Matemáticas, Lima, Perú. e-mail: raul_izaguirre2222 đayahoo.es 


\section{Notations and Preliminaries}

We denote

$$
(w, z)=\int_{0}^{1} w(x) z(x) d x \quad, \quad|z|_{q}^{q}=\int_{0}^{1}|z(x)|^{q} d x
$$

For simplicity, we alirays use $|$.$| to denote |.|_{2}$

By $V$ we denote the Hilbert space

$$
V=\left\{w \in H^{1}(0,1): w(0)=0\right\}
$$

Now, we set

$$
\begin{aligned}
& J(u)=\frac{1}{2}\left|u_{x}\right|^{2}-\frac{\mu}{q+1}|u|_{q+1}^{q+1} \\
& I(u)=\left|u_{x}\right|^{2}-\mu|u|_{q+1}^{q+1}
\end{aligned}
$$

and define the stable set $W$ by

$$
[W=\{u \in V: I(u)>0\} \cup\{\theta\}]
$$

Consider $\sigma: \mathbb{R} \longrightarrow \mathbb{R}$ is a nonincreasing function of class $\mathrm{C}^{1}$ on $\mathbb{R}_{+}$such that

$$
\int_{0}^{\infty} \sigma(\tau) d \tau=+\infty
$$

We need the following

Lemma 2.1. Let $E: \mathbb{R}_{+} \longrightarrow \mathbb{R}_{+}$be a nonincreasing function

and $\phi: \mathbb{R}_{+} \longrightarrow \mathbb{R}_{+}$is a increasing function of class $\mathrm{C}^{2}$ such that

$$
\phi(0)=0, \quad \phi(t) \longrightarrow+\infty \text { as } t \longrightarrow+\infty
$$

Assume that there exists $p \geq 1$ and $A>0$ such that

$$
\int_{S}^{+\infty} E^{(p+1) / 2}(t) \phi^{\prime}(t) d t \leq A E(S), \quad, 0 \leq S<+\infty
$$

then

$$
E(t) \leq\left\{\begin{array}{c}
c E(0) e^{-w \phi(t)}, \forall \mathrm{t} \geq 0, \text { if } p=1 \\
c E(0)(1+\phi(t))^{-2 /(p-1)}, \forall \mathrm{t} \geq 0, \text { if } p=1
\end{array}\right.
$$

where $c$ and $w$ are positive constants independent of the initial energy $E(0)$. Next by setting

$$
E(t) \equiv E(u(t))=\frac{1}{2}\left|u_{t}(t)\right|^{2}+J(u(t))
$$

we obtain the main result 


\section{Global Existence and Exponential Decay}

Theorem 3.1. Suppose that $q>1$ and $\mu>0$. If $u^{0} \in W \cap H^{2}(0,1), u^{1} \in V$ verifying the compatibility condition

$$
u_{x}^{0}(1)+\sigma(0) u^{1}(1)=0
$$

and

$$
=\frac{\mu}{a} C_{*}^{q+1}\left[\frac{2(q+1)}{a(q-1)} E(0)\right]^{(q-1) / 2}<1
$$

then the problem (1.1) admits a global solution $u=u(x, t)$ satisfying

$$
\mid \begin{aligned}
& u \in L^{\infty}\left(\left[0,+\infty\left[; W \cap H^{2}(0,1)\right)\right.\right. \\
& u_{t} \in L^{\infty}([0,+\infty[; V) \\
& u_{t t} \in L^{\infty}\left(\left[0,+\infty\left[; L^{2}(0,1)\right)\right.\right.
\end{aligned} .
$$

Furthermore, the energy determined by the solution $u$ has the following decay rate

$$
E(t) \leq C_{0} e^{-\gamma t}
$$

where $C_{0}$, and $\gamma$ are positive constants .

Proof. We shall employ the Galerkin method. Let $\left\{\omega_{j}\right\}_{j=1}^{\infty}$ be a complete orthonormal system of $V$ such that

$$
\left\{u^{0}, u^{1}\right\} \in \operatorname{Spam}\left\{\omega^{0}, \omega^{1}\right\}
$$

We define as is usual, the approximate solutions

$$
u_{m}(t)=\sum_{j=1}^{m} g_{j, m}(t) \omega_{j}, m=1,2, \ldots
$$

where $g_{j, m}(j=1,2, \ldots, m)$ are defined by

$$
\begin{gathered}
\left(u_{t t}^{m}(t), \omega_{j}\right)+\left(u_{x}^{m}(t), \omega_{j, x}\right)+\sigma(t) u_{t}(1, t) \omega_{j}(1)+ \\
+\mu\left(\left|u^{m}\right|^{q-1} u^{m}, \omega_{j}\right)=0, \quad 0 \leq j \leq m \\
u^{m}(x, 0)=u^{0}(x), \quad u_{t}^{m}(x, 0)=u^{1}(x)
\end{gathered}
$$

Then the system $(3.4)$ - (3.5) has a unique solution $u^{m}$ on some interval $\left[0, T_{m}[\right.$ with $0<T_{m} \leq+\infty$. The estimates to follow permit us to extend the solution $u^{m}$ to the whole interval $[0,+\infty[$ and take the limit in (3.4)-(3.5).For sake a simplicity,henceforth, we will write $u$ instead of $u^{m}$.

Estimative I.- Let us multiply equation (3.4) by $g_{j, m}^{\prime}(t)$ and summing up the product result in $j$.we arrive at

$$
\frac{d}{d t} E^{m}(t)+\sigma(t)\left|u_{t}(1, t)\right|^{2}=0 . .
$$


Integrating from 0 to the above relation,it follows that

$$
E^{m}(t)+\int_{0}^{t} \sigma()\left|u_{t}(1, \quad)\right|^{2} d=E^{m}(0)=E(0)
$$

In particular $E^{m}(t)$ is non-increasing on $[0,+\infty[$ and

$$
E^{m}(t) \leq E(0)
$$

Now ,to obtain a priori estimate, we need the following result

Lemma 3.1. Let $u(t)$ be a solution to the problem (3.4)-(3.5) with $u^{0} \in W$ and $u^{1} \in L^{2}(0,1)$. If $\alpha<1$ then $u(t) \in W$, that is, for all $t \in[0, T]$

$$
I(u(t))>0
$$

Proof. From the continuity of $u(t)$ and since $u^{0} \in W$, it follows that

$$
I(u(t)) \geq 0
$$

for all $t$ belonging to some neighborhood of $t=0$. Let $T_{\text {máx }}$ be a maximal time where (3.9) holds on $\left[0, T_{\text {maxx }}[\right.$. Then,from (3.9) we deduce that

$$
\begin{aligned}
J(u(t)) & =\frac{1}{2}\left|u_{x}(t)\right|^{2}-\frac{\mu}{q+1}|u(t)|_{q+1}^{q+1} \\
& =\frac{1}{q-1} I(u(t))+\frac{(q-1)}{2(q+1)}\left|u_{x}(t)\right|^{2} \\
& \geq \frac{(q-1)}{2(q+1)}\left|u_{x}(t)\right|^{2} \quad \text { on }\left[0, T_{\text {máx }}[\right.
\end{aligned}
$$

Consequently,having in mind that $E(t)$ is a non-increasing function, we get

$$
\begin{aligned}
\left|u_{x}(t)\right|^{2} & \leq \frac{2(q+1)}{(q-1)} J(u(t)) \\
& \leq \frac{2(q+1)}{(q-1)} E(u(t)) \\
& \leq \frac{2(q+1)}{(q-1)} E(0) \text { on }\left[0, T_{\text {máx }}[\right.
\end{aligned}
$$

It follows from the Sobolev-Poincaré inequality, the hypothesis and (3.8) that

$$
\begin{aligned}
\mu|u|_{q+1}^{q+1} & \leq \mu C_{*}^{q+1}\left|u_{x}(t)\right|^{q+1}=\mu\left|u_{x}(t)\right|^{q-1} \cdot\left|u_{x}(t)\right|^{2} \\
& \leq \mu C_{*}^{q+1}\left[\frac{2(q+1)}{(q-1)} E(0)\right]^{(q-1) / 2} \cdot\left|u_{x}(t)\right|^{2} \\
& <\left|u_{x}(t)\right|^{2} \text { on }\left[0 . T_{\text {máx }}[\right.
\end{aligned}
$$

From (3.11) and (3.12) we obtain 


$$
\mu|u|_{q+1}^{q+1}<\left|u_{x}(t)\right|^{2} \quad \text { on } \quad\left[0 . T_{\text {máx }} \mid\right.
$$

Therefore we get $I(u(t))>0$ on $\left[0, T_{\operatorname{máx}}[\right.$.

This implies that we can take $T_{\text {máx }}=T_{m}$. This completes the proof of lemma 3.1

Using Lemma 3 , we can deduce a priori bound

$$
\begin{aligned}
E(t) & \equiv \frac{1}{2}\left|u_{t}(t)\right|^{2}+J(u(t)) \\
& \geq \frac{1}{2}\left|u_{t}(t)\right|^{2}+\frac{1}{q+1} I(u(t))+\frac{(q-1)}{2(q+1)}\left|u_{x}(t)\right|^{2} \\
& \geq \frac{1}{2}\left|u_{t}(t)\right|^{2}+\frac{(q-1)}{2(q+1)}\left|u_{x}(t)\right|^{2}
\end{aligned}
$$

Thus

$$
\frac{1}{2}\left|u_{t}(t)\right|^{2}+\frac{(q-1)}{2(q+1)}\left|u_{x}(t)\right|^{2}+\int_{0}^{t} \sigma()\left|u_{t}(1, \quad)\right|^{2} d \leq E(0) .
$$

To obtain the next estimate, we use the differentiated equation of standard way., it is easy and we omit details.

Now, we prove the decay rate of the energy.

From now on , we denote by c various positive constants which may be different at different occurrences. We multiply the first equation of (1.1) by $2 E^{r} \phi^{\prime} x u_{x}$, where $\phi$ is a function satisfying all the hypotheses of Lemma 1. We obtain:

$$
\begin{aligned}
0= & \int_{S}^{T} E^{r} \phi^{\prime}\left(u_{t t}-u_{x x}-\mu|u|^{q-1} u, 2 x u_{x}\right) d t=\left.2 E^{r} \phi^{\prime}\left(u_{t}, x u_{x}\right)\right|_{S} ^{T} \\
& -2 \int_{S}^{T}\left(E^{r} \phi^{\prime \prime}+r E^{r-1} E^{\prime} \phi^{\prime}\right)\left(u_{t}, x u_{x}\right) d t+\int_{S}^{T} E^{r} \phi^{\prime}\left|u_{t}(t)\right|^{2} d t \\
& -\int_{S}^{T} E^{r} \phi^{\prime} u_{t}^{2}(1, t) d t+\int_{S}^{T} E^{r} \phi^{\prime} u_{x}^{2} d t \\
& -\int_{S}^{T} E^{r} \phi^{\prime} u_{x}^{2}(1, t) d t-2 \int_{S}^{T} E^{r} \phi^{\prime}\left(\mu|u(t)|^{q-1} u(t), x u_{x}(t)\right) d t
\end{aligned}
$$

Then, we get

$$
\begin{aligned}
& \int_{S}^{T} E^{r+1} \phi^{\prime} d t=2 \int_{S}^{T}\left(E^{r} \phi^{\prime \prime}+r E^{r-1} E^{\prime} \phi^{\prime}\right)\left(u_{t}, x u_{x}\right) d t \\
& -\left.2 E^{r} \phi^{\prime}\left(u_{t}, x u_{x}\right)\right|_{S} ^{T}+\int_{S}^{T} E^{r} \phi^{\prime} u_{t}^{2}(1, t) d t+\int_{S}^{T} E^{r} \phi^{\prime} u_{x}^{2}(1, t) d t \\
& +2 \int_{S}^{T} E^{r} \phi^{\prime}\left(\mu|u(t)|^{q-1} u(t), x u_{x}(t)\right) d t-\frac{2 \mu}{q+1} \int_{S}^{T} E^{r} \phi^{\prime}|u|_{q+1}^{q+1} d t
\end{aligned}
$$

But

$$
\begin{aligned}
\left|\left(|u(t)|^{q-1} u(t), x u_{x}(t)\right)\right| & \leq|u(t)|_{2 q}^{q}\left|u_{x}(t)\right| \\
& \leq|u(t)|_{2}^{(1-\theta) q} C_{*}^{\theta q}\left|u_{x}(t)\right|^{\theta q+1} .0<\theta<1
\end{aligned}
$$


where we have used the interpolation inequality and the fact: that $|u(t)|_{r} \leq C_{*}\left|u_{x}(t)\right| \quad, \forall r$.

From Young inequality, we have for all $\varepsilon>0$, that

$$
\left|\left(|u(t)|^{q-1} u(t), x u_{x}(t)\right)\right| \leq c_{\varepsilon}|u(t)|^{2}+\varepsilon k\left|u_{x}(t)\right|^{2}
$$

where $k=[E(0)]^{[q(\theta+1)-2] / 2[2-(1-\theta) q]} c_{*}^{\theta q}$. Similarly, we obtain

$$
|u|_{q+1}^{q+1} \leq \epsilon E(t)+c_{\epsilon}|u(t)|^{2}
$$

Now ,using (4.12)-(4.13),(3.17) and the boundary condition we get

$$
\begin{aligned}
& \delta_{1} \int_{S}^{T} E^{r+1} \phi^{\prime} d t \leq 2 \int_{S}^{T}\left(E^{r} \phi^{\prime \prime}+r E^{r-1} E^{\prime} \phi^{\prime}\right)\left(u_{t}, x u_{x}\right) d t \\
& -\left.2 E^{r} \phi^{\prime}\left(u_{t}, x u_{x}\right)\right|_{S} ^{T}+\int_{S}^{T} E^{r} \phi^{\prime} u_{t}^{2}(1, t) d t \\
& +\int_{S}^{T} E^{r} \phi^{\prime} \sigma^{2}(t) u_{t}^{2}(1, t) d t+\delta_{2} \int_{S}^{T} E^{r} \phi^{\prime} \quad|\dot{u(t)}|^{2} d t
\end{aligned}
$$

Our main now is to estimate the last term of (3.20).In order to obtain it,let us prove the following result, where $T_{0}$ is a positive constant which is sufficiently large.

Lemma 3.2. For all $T>T_{0}$, there exists $C>0$ independent of the initial data,such that the solution $u$ of (1.1) satisfies

$$
\int_{S}^{T}|u(t)|^{2} d t \leq C \int_{S}^{T}\left|u_{t}(1, t)\right|^{2} d t
$$

for $0 \leq S<T<+\infty$

Proof. We will argue by contradiction.

Define

$$
\phi(t)=\int_{0}^{t} \sigma(\tau) d \tau
$$

It is clear that $\phi$ is a nondecreasing function of class $C^{2}$ on $\mathbb{R}_{+}$and the hypothesis (2.1) ensures that

$$
\phi(t) \longrightarrow+\infty \text { as } t \longrightarrow+\infty
$$

From (3.20)-(3.22), taking $r=0$ we deduce that :

$$
\int_{S}^{T} E \phi^{\prime} d t \leq c E(S)
$$

and thanks to Lemma 1 we arrive at

$$
E(t) \leq C E(0) e^{-w \phi(t)}
$$

Thus the proof of theorem 2 is completed. 


\section{REFERENCES}

[1] F.D. Araruma, A.B. Maciel, Existence an boundary stabilization of the semilinear wave equation. Nonlinear Analysis (2007) Vol 67, 4 , 1288-1305.

[2] E. Cabanillas Lapa, Z. Huaringa S., B Godoy T., The transmission problem with nonlinear damping and source terms, Appl. Math and Inf. Sc. Int. J., 2 (2) (2008), 187-209.

[3] M. Cavalcanti, V. Domingos Cavalcanti, J.A. Soriano; Existence and boundary stabilization of a nonlinear hyperbolic equation with time dependent coefficients, Elec J. Diff. Eq. 8 (1998), 1-21.

[4] K. Ono; A stretched string equation with a boundary dissipation, Kyushu J. Math, 48 (1994), 265-281

[5] P. Martinez, A new method to obtain decay rate estimates for dissipative systems, ESAIM Control OPtim. Cal. Var. 4 (1999), 419-444.

[6] M. Tucsnak; Boundary stabilization for the stretched string equation, Diff. Integ. Eq., 6 (1993), 925-935. 